\title{
Correlation of Monthly Median Transmission Loss and Refractive Index Profile Characteristics
}

\author{
B. R. Bean and B. A. Cahoon
}

(July 14, 1960; revised August 5, 1960)

\begin{abstract}
The difference in the monthly mean values of the refractive index at ground level and at one kilometer above the ground level is often used for the purpose of predicting the annual cycle of radio transmission loss. The present study investigates the possibility of utilizing differences to heights other than one kilometer. A comparison of 100 megacycles per second transmission ioss recorded over twenty-one paths with various refractivity differences from the surface to three kilometers reveals that the surface value of the refractive index yields as good a correlation as any of the refractive index differences due to the high correlation between the surface values and these differences; therefore the more accessible surface value can be effectively substituted for the differences. Specifying the refractive index profile at two or three additive points and using multiple correlation techniques does not significantly increase the correlation.

The use of radio data over the same path does not significantly improve the correlation over that obtained from only meteorological data, indicating the very practical result that inexpensive meteorological data may be used to predict the seasonal trend of VHF radio field strengths with as much accuracy as expensive radio path measurements.
\end{abstract}

\section{Introduction}

Current engineering practice in estimating the level of bey ond-the-horizon VHF-UHF radio field strengths $\left[\begin{array}{lll}1 & \text { to } & 5\end{array}\right]^{2}$ consists of determining an average level for a given distance and then adjusting this average level for climatic and seasonal differences by reference to common meteorological measurements of pressure, temperature, and humidity as expressed by the radio refractive index, $n$. Although past investigations have principally utilized the difference in $n$ between the earth's surface and $1 \mathrm{~km}$ above the earth's surface, better results might be obtained by using differences to heights other than $1 \mathrm{~km}$ or between different levels on the profile. It is the purpose of this study to explore this possibility via the correlation of the annual cycles of monthly median radio transmission loss and $n$ gradients obtained over a variety of height increments. The sections that follow deal with the available radio and meteorological data, deriving correlations between the two and discussing their significance on a regional and a statistically-combined basis.

\section{Radio and Meteorological Data}

The radio data used in the present studies are the $100 \mathrm{Mc} / \mathrm{s}$ monthly median transmission losses for the 21 transmission paths listed in table 1. All data correspond to the hours of the 0300 and 1500 G.m.t. radiosonde observations $(1000$ and 2200 e.s.t.). These data represent climatic conditions ranging from those of New England (path 19) to the central and southeastern seaboard (paths 17

Contribution from Central Radio Propagation Laboratory, National Bureau of Standards, Boulder, Colo.

2 Figures in brackets indicate the literature references at the end of this paper.
TABLE 1

\begin{tabular}{|c|c|c|c|c|c|c|}
\hline Path & Call letters & $\begin{array}{l}\text { Transmitter } \\
\text { location }\end{array}$ & $\begin{array}{l}\text { Receiver } \\
\text { location }\end{array}$ & $\begin{array}{c}\text { Fre- } \\
\text { quency }\end{array}$ & $\begin{array}{l}\text { Dis- } \\
\text { tance }\end{array}$ & $\theta(\mathrm{mr})$ \\
\hline 1 & KXYZ & Houston, Tex & Austin, Tex & $\begin{array}{r}\mathrm{Mc} / \mathrm{s} \\
96.5\end{array}$ & $\begin{array}{c}\mathrm{km} \\
237.9\end{array}$ & 20.32 \\
\hline $\begin{array}{l}1 \\
2\end{array}$ & KPRC & Houston, Tex & $\begin{array}{l}\text { Austin, Tex..- } \\
\text { Austin, Tex..- }\end{array}$ & $\begin{array}{r}90.5 \\
102.9\end{array}$ & 237.9 & 21.00 \\
\hline 3 & KIXL & Dallas, Tex & Austin, Tex... & 104.5 & 283.1 & 32.38 \\
\hline 4 & KWKH & Shreveport, La...- & Austin, Tex..- & 94.5 & 446. 4 & 47. 36 \\
\hline 5 & KLTI & Longview, Tex...- & Austin, Tex & 105. 9 & 365.6 & 40.40 \\
\hline 6 & WFAA & Dallas, Tex_. & Austin, Tex... & 97.9 & 280.3 & 32.54 \\
\hline 7 & W & Chic & Urbana, Ill & 95 & 20 & 16.13 \\
\hline 8 & & is, Ind. & Urbana, Ill & 93 & 223.7 & 20.88 \\
\hline 9 & $\mathrm{~K}$ & St. Louis, Mo & Urbana, Ill & 93.7 & 235.8 & 19.34 \\
\hline 10 & WH & Columbus, Ohio .- & Hudson, Ohio & 98.7 & 201.0 & 19.42 \\
\hline 11 & W & Columbus, $\mathrm{O}$ & Hudso & 92.3 & 195. 1 & 20.12 \\
\hline 12 & & Pittsburgh, $\mathrm{Pa}$ & $\begin{array}{l}\text { State College, } \\
\mathrm{Pa} \text {. }\end{array}$ & 99 & 188.5 & 30.44 \\
\hline 13 & WEST & Easton, $\mathrm{Pa}_{-.}$ & State College, & 107. 9 & 224.2 & 36.67 \\
\hline 14 & WTOP & Washington, D.C_ & $\begin{array}{l}\text { State College, } \\
\text { Pa. }\end{array}$ & 96.3 & 215.8 & 63.47 \\
\hline 15 & KFSD & San Diego, Calif..- & $\begin{array}{l}\text { Santa Ana, } \\
\text { Calif. }\end{array}$ & 94.1 & 136.3 & 28.97 \\
\hline 16 & KFOR & Lincoln, Nebr...... & Grand Island, & 102. 9 & 150.0 & 14. 59 \\
\hline 17 & WCAC & Anderson, S.C & $\begin{array}{l}\text { Powder } \\
\text { Springs, Ga }\end{array}$ & 101.1 & 205.2 & 19.81 \\
\hline 18 & & Pitts & Hudson, Ohio & 92.9 & 155.6 & 12.15 \\
\hline 19 & WTIC & Hartford, Conn & Millis, Mass . & 96.5 & 129. 9 & 16. 29 \\
\hline 0 & NBS- & $\begin{array}{l}\text { Cheyenne Mt. } \\
\text { Colo. }\end{array}$ & $\begin{array}{l}\text { Haswell, } \\
\text { Colo. }\end{array}$ & 92.0 & 155.8 & 6.469 \\
\hline 21 & WIP-FM & Philadelphia, $\mathrm{Pa}_{--}$ & Laurel, Md... & 93.3 & 167.7 & 12.04 \\
\hline
\end{tabular}

and 21) the Gulf States (paths 1 to 6), Great Lakes (paths 7, 11, and 18), the high plains (paths 16 and 20), and the Pacific Coast (path 15). Examples of annual cycles of monthly median basic transmission loss for four geographically representative radio paths are given on figure 1. It is quite clear that, with but minor variation, the transmission loss from each path follows a rather definite annual cycle, the loss being low in the summer months and high in the winter months. It appears to be quite significant that similar annual cycles are observed in such different climatic regions as the Appalachian Mountains of Pennsylvania and southern California coast. 




Figure 1. Annual cycles of monthly median basic transmission loss for four geographically diverse radio paths.

These annual cycles plus the data indicated by table 1 were used as a test of various radio meteorological parameters that might be used in propagation studies. The refractive index gradients were prepared from 6-yr means of temperature, pressure, and humidity as a function of height by the National Weather Records Center of the U.S. Weather Bureau. These data were then converted to

$$
N=(n-1) 10^{6}
$$

by means of the Smith-Weintraub relationship [6]. Simple differences of the value of $N$ at the earth's surface, $N_{s}$, and its value at $0.1,0.2,0.3,0.5,0.7$, $1.0,2.0$, and $3.0 \mathrm{~km}$ above the earth's surface were obtained. This procedure is illustrated for an exponential curve on figure 2. For example, the value of the difference to $500 \mathrm{~m}, \Delta N_{0.5}$, is determined by

$$
\Delta N_{0.5}=N_{s}-N_{0.5} .
$$

The variations of transmission loss were also compared with those of $N_{s}$ since it has received such wide engineering applications [ 1 to 4,7 to 9 ].

\section{Choice of Statistical Model}

When analyzing two variables for a possible interrelation one has available many statistical techniques such as linear, multiple, and polynomial regression. Individual graphs of transmission loss and $\Delta N_{h}$ were prepared for each of the gradient levels on each of the propagation paths to aid in the choice of an appropriate statistical model. Visual investigation of these data, examples of which are shown on figures 3 and 4, reveals the presence of a large random component that masks any obvious nonlinear relation between the variables. On this basis it was decided that use of nonlinear regression techniques was an unnecessary complication at this stage of the analysis, and the simple linear regression model was adopted.

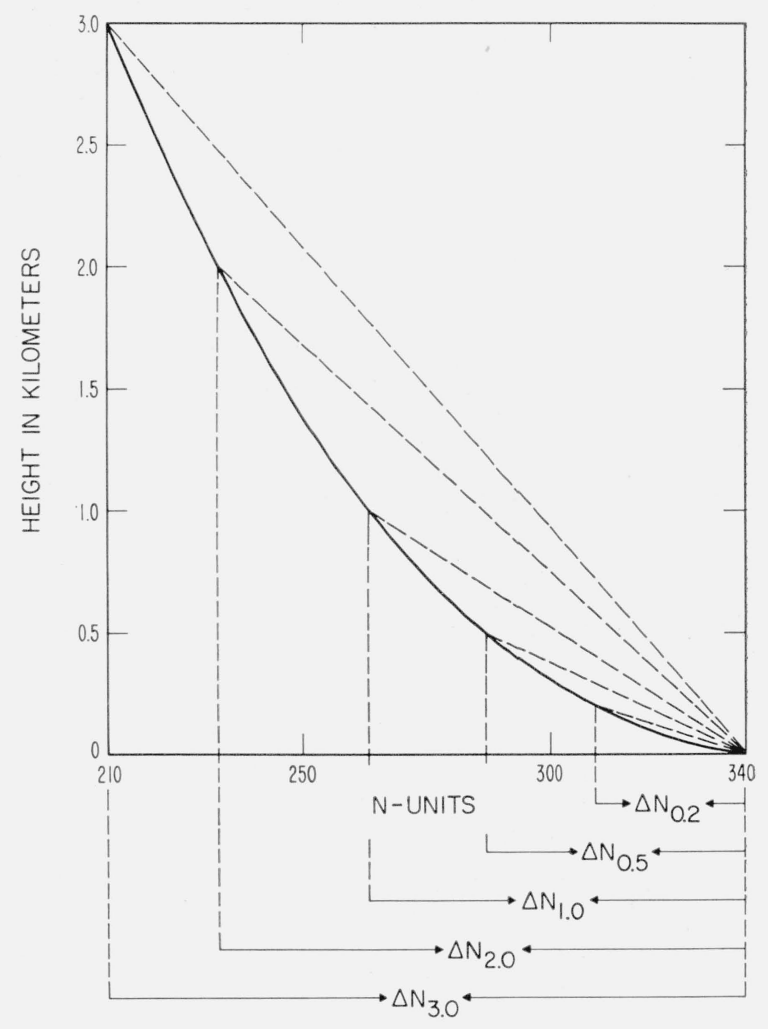

Figure 2. Graphical representation of the determination of various $\mathrm{N}$ differences in an average atmosphere.

\section{Statistical Considerations}

We are here concerned with the degree to which the annual cycle of radio transmission loss may be predicted from the several $\Delta N_{h}$ values described above under the assumption of a linear regression model. This is done on a quantitative basis by determining the linear correlation coefficient, $r_{y \cdot x}$, between a dependent variable, $y$, (in this case the transmission loss) and an independent variable $x$ (whichever $\Delta N_{h}$ we are considering). The reason for determining the correlation coefficient can be understood more easily in terms of the standard error of estimate, $(S E)_{y}$, which is given by

$$
(S E)_{y}=s_{y}\left(1-r_{y \cdot x}^{2}\right)^{1 / 2}
$$

where $s_{y}$ is the standard deviation of the dependent variable. Equation (3) allows one to evaluate quantitatively the degree to which one may predict the variations of $y$ by knowing its correlation with $x$ (and the concomitant regression equation). Thus it is seen that if $y$ is completely determined from $x$, and $r_{y \cdot x}=1$, then $(S E)_{y}=0$. Conversely, if $x$ and $y$ are totally independent, then $r_{y \cdot x}=0$, and $(S E)_{y}=s_{y}$, and there is no advantage gained by attributing variations of $y$ to $x$. We may define the improvement factor

$$
k=100\left[\frac{s_{y}-(S E)_{y}}{s_{y}}\right],
$$


TABLE 2. Coefficient of correlation between monthly median transmission loss and indicated meteorological variable.

\begin{tabular}{|c|c|c|c|c|c|c|c|c|c|c|}
\hline Path & $\begin{array}{c}\text { Pieces of } \\
\text { data }\end{array}$ & $N_{s}$ & $\Delta N_{0.1}$ & $\Delta N_{0.2}$ & $\Delta N_{0.3}$ & $\Delta N_{0.5}$ & $\Delta N_{0.7}$ & $\Delta N_{1,0}$ & $\Delta N_{2.0}$ & $\Delta N_{3,0}$ \\
\hline $\begin{array}{l}1 \\
2 \\
3 \\
4 \\
5\end{array}$ & $\begin{array}{l}38 \\
36 \\
68 \\
41 \\
23\end{array}$ & $\begin{array}{r}0.586 \\
.618 \\
.787 \\
.774 \\
.672\end{array}$ & $\begin{array}{r}0.504 \\
.462 \\
.670 \\
.619 \\
.549\end{array}$ & $\begin{array}{r}0.517 \\
.527 \\
.690 \\
.623 \\
.541\end{array}$ & $\begin{array}{r}0.525 \\
.552 \\
.707 \\
.640 \\
.536\end{array}$ & $\begin{array}{r}0.553 \\
.593 \\
.724 \\
.654 \\
.539\end{array}$ & $\begin{array}{r}0.589 \\
.614 \\
.737 \\
.657 \\
.533\end{array}$ & $\begin{array}{r}0.612 \\
.632 \\
.768 \\
.706 \\
.589\end{array}$ & $\begin{array}{r}0.626 \\
.659 \\
.787 \\
.714 \\
.617\end{array}$ & $\begin{array}{r}0.624 \\
.651 \\
.786 \\
.732 \\
.627\end{array}$ \\
\hline $\begin{array}{r}6 \\
7 \\
8 \\
9 \\
10\end{array}$ & $\begin{array}{r}7 \\
22 \\
48 \\
24 \\
74\end{array}$ & $\begin{array}{r}.940 \\
.714 \\
.726 \\
.588 \\
.506\end{array}$ & $\begin{array}{l}.806 \\
.539 \\
.713 \\
.626 \\
.527\end{array}$ & $\begin{array}{l}.850 \\
.559 \\
.729 \\
.643 \\
.540\end{array}$ & $\begin{array}{l}.851 \\
.567 \\
.729 \\
.639 \\
.540\end{array}$ & $\begin{array}{l}.883 \\
.645 \\
.742 \\
.627 \\
.550\end{array}$ & $\begin{array}{l}.890 \\
.695 \\
.763 \\
.638 \\
.540\end{array}$ & $\begin{array}{l}.909 \\
.711 \\
.766 \\
.626 \\
.556\end{array}$ & $\begin{array}{l}.916 \\
.727 \\
.767 \\
.627 \\
.532\end{array}$ & $\begin{array}{l}.925 \\
.718 \\
.745 \\
.608 \\
.518\end{array}$ \\
\hline $\begin{array}{l}11 \\
12 \\
13 \\
14 \\
15\end{array}$ & $\begin{array}{l}64 \\
41 \\
26 \\
12 \\
28\end{array}$ & $\begin{array}{l}.525 \\
.868 \\
.785 \\
.935 \\
.797\end{array}$ & $\begin{array}{r}.542 \\
.778 \\
.590 \\
-.733 \\
-.128\end{array}$ & $\begin{array}{r}.542 \\
.858 \\
.724 \\
.887 \\
-.228\end{array}$ & $\begin{array}{r}.534 \\
.871 \\
.734 \\
.886 \\
-.246\end{array}$ & $\begin{array}{r}.552 \\
.874 \\
.725 \\
-.893 \\
-.134\end{array}$ & $\begin{array}{l}.554 \\
.866 \\
.743 \\
.901 \\
.731\end{array}$ & $\begin{array}{l}.575 \\
.873 \\
.778 \\
.928 \\
.802\end{array}$ & $\begin{array}{l}.556 \\
.874 \\
.802 \\
.940 \\
.787\end{array}$ & $\begin{array}{l}.539 \\
.869 \\
.800 \\
.938 \\
.814\end{array}$ \\
\hline $\begin{array}{l}16 \\
17 \\
18 \\
19 \\
20 \\
21\end{array}$ & $\begin{array}{l}17 \\
17 \\
30 \\
13 \\
13 \\
38\end{array}$ & $\begin{array}{l}.626 \\
.373 \\
.803 \\
.744 \\
.115 \\
.652\end{array}$ & $\begin{array}{l}.542 \\
.247 \\
.809 \\
.214 \\
.364 \\
.579\end{array}$ & $\begin{array}{l}.576 \\
.298 \\
.830 \\
.686 \\
.373 \\
.806\end{array}$ & $\begin{array}{l}.619 \\
.314 \\
.836 \\
.779 \\
.299 \\
.781\end{array}$ & $\begin{array}{l}.654 \\
.370 \\
.832 \\
.782 \\
.292 \\
.761\end{array}$ & $\begin{array}{l}.660 \\
.384 \\
.797 \\
.775 \\
.270 \\
.722\end{array}$ & $\begin{array}{l}.666 \\
.466 \\
.791 \\
.760 \\
.214 \\
.688\end{array}$ & $\begin{array}{l}.655 \\
.455 \\
.787 \\
.778 \\
.118 \\
.655\end{array}$ & $\begin{array}{r}.636 \\
.421 \\
.799 \\
.768 \\
.117 \\
.647\end{array}$ \\
\hline
\end{tabular}

Mean values (omitting path 20)

\begin{tabular}{|c|c|c|c|c|c|c|c|c|c|c|}
\hline $\begin{array}{l}r(z) \\
k[r(\bar{z})]\end{array}$ & $\begin{array}{l}667 \\
667\end{array}$ & $\begin{array}{l}0.694 \\
28.0 \%\end{array}$ & $\begin{array}{l}0.578 \\
18.4 \%\end{array}$ & $\begin{array}{l}0.633 \\
22.6 \%\end{array}$ & $\begin{array}{l}0.640 \\
23.2 \%\end{array}$ & $\begin{array}{l}0.655 \\
24.4 \%\end{array}$ & $\begin{array}{l}0.676 \\
26.4 \%\end{array}$ & $\begin{array}{l}0.702 \\
28.8 \%\end{array}$ & $\begin{array}{l}0.704 \\
29.0 \%\end{array}$ & $\begin{array}{l}0.700 \\
28.6 \%\end{array}$ \\
\hline
\end{tabular}

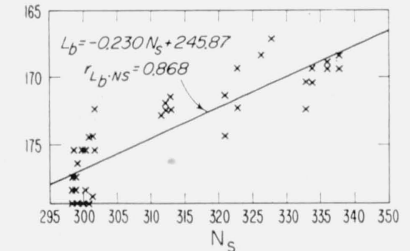

WJAS FM - PATH 12 TRANSMITTER: PITTSBURGH, PA. RECEIVER: STATE COLLEGE, PA: DISTANCE : 188.5 KILOMETERS $\theta: 30.44$ MILLIRADIANS


FIgURE 3. Monthly median basic transmission loss versus $\mathrm{N}_{\mathrm{s}}$ or $\Delta \mathrm{N}_{\mathrm{h}}$ for Path 12 (Pittsburgh to State College, Pa). as the percentage reduction of uncertainty of predicting $y$ from knowledge of its correlation with $x$.

It is frequently desirable to estimate the average value of the correlation coefficient when dealing with several correlation coefficients between the same variables but derived in different climatic regions. Since $r$ is not normally distributed it is desirable to convert $r$ to Fisher's $z$,

$$
z=\frac{1}{2}\left[\log _{e}(1+r)-\log _{e}(1-r)\right]
$$

whicn is more nearly normally distributed, obtain the average of $z$, and convert this average $\bar{z}$ to an estimate of $\bar{r}[10]$.

\section{Comparison of Annual Cycles}

Individual correlation coefficients of the monthly median transmission loss and the mean value of the various refractive index gradients were determined for each path and are listed in table 2 . Figure 5 depicts the relative behavior of $r$ versus $N$ difference to various heights for the same four radio paths as those graphed in figure 1 . It can be noted from figure 5 and table 2 that the magnitude of the correlation coefficients is generally lowest when determined versus $\Delta N_{0.1}$ and rises with increasing $\Delta h$ until the maximum value is reached at 1.0 or $2.0 \mathrm{~km}$.

Table 2 also lists the average correlation coefficients [10], indicating that the correlation of radio transmission loss with $N_{s}$ is as large as those obtained with any value of $\Delta N_{h}$.

There are some notable exceptions to the above observations. For example, path 18 (Pennsylvania to Ohio) and path 9 (Missouri to Illinois) displayed a fairly uniform correlation for all height increments with a very small range of coefficients. Path 19, 
where the $0.5 \mathrm{~km}$ level evinced the highest correlation, and patb 21, where the maximum correlation appeared at $0.2 \mathrm{~km}$, also had a very low range with the exception of the $0.1-\mathrm{km}$ level where the correlation coefficient was significantly lower.

The low correlations for path 20 might arise from the fact that this path is a borderline knife-edge diffraction case, as indicated by the low value of the angular distance, $\theta$.

Perhaps the most interesting case is that of path 15, San Diego to Santa Ana, California, where the largest correlations are found between the transmission loss and $N_{s}$ and gradients for height increments in excess of $0.7 \mathrm{~km}$. The correlation coefficients for height increments below $0.7 \mathrm{~km}$ are not only relatively small but are negative. This physically unrealistic behavior, shown in more detail in figures 4 and 5, may be explained by the presence of the well-known southorn California coastal inversion which occurs at about $0.7 \mathrm{~km}$ and is known to exert a dominating influence upon radio field strengths in that region [11, 12]. The interesting conclusion here is that the variations of radio fields follow those of $N_{s}$ and any of the $N$ differences to heights above the base of the inversion but do not follow the intermediate differences.


TRANSMITTER: SAN DIEGO, CALIF.

RECEIVER: SANTA ANA, CALIF. DISTANCE: 136.3 KILOMETERS $\theta: 28.97$ MILLIRADIANS
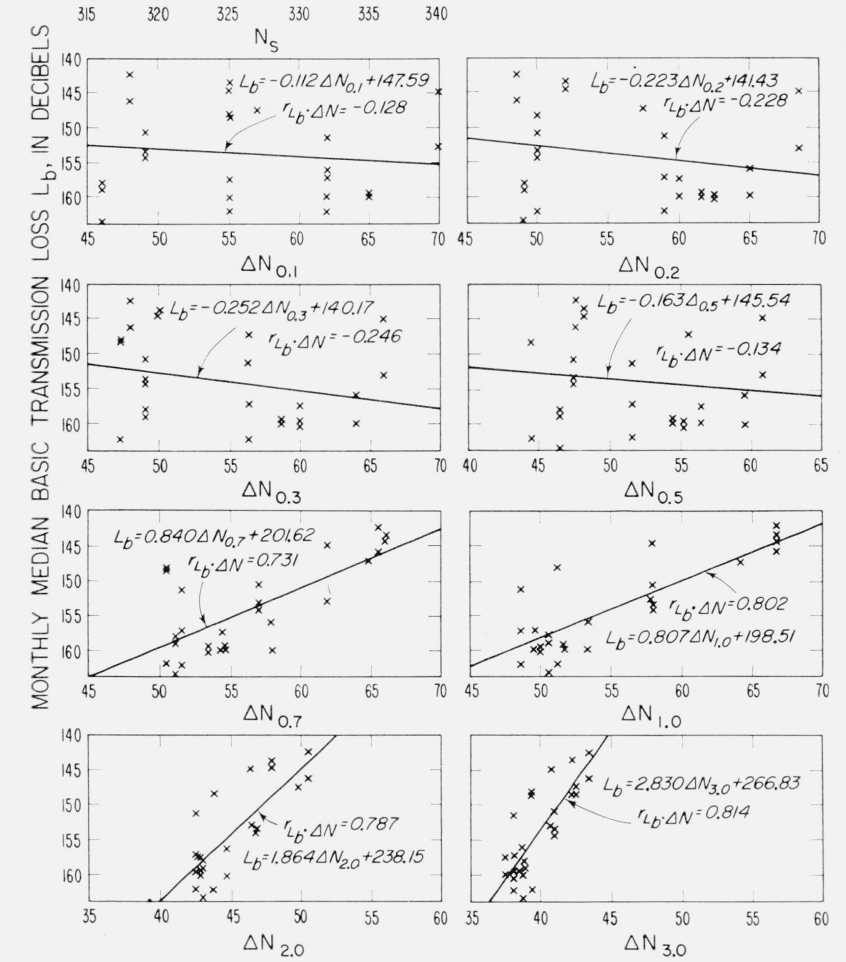

FIgURE 4. Monthly median basic transmission loss versus $\mathrm{N}_{\mathrm{s}}$ or $\Delta \mathrm{N}_{\mathrm{h}}$ for Path 15 (San Diego to Santa Ana, Calif.).

\section{Other Measures of the Gradient}

The preceding analysis has been concerned with the correlation of transmission loss and $\Delta N_{h}$ when $h$ takes on several different values. It is also profitable to examine the correlation of transmission loss and differences in index taken between various points on the $N$ profile such as has been found useful in Ger-


FIGURE 5. Correlation coefficients of monthly median basic transmission loss versus height in meters of $\Delta \mathrm{N}_{\mathrm{h}}$ for four geographically diverse paths.

many by Grosskopf [13]. Another profile measure is Misme's "useful gradient" [14], $G$, given by ${ }^{3}$

$$
G=\frac{2 \Delta N_{0}+\Delta N_{c}}{3}
$$

where $\Delta N_{0}$ is the initial gradient and $\Delta N_{c}$ is the gradiant at the crossover height of the radio horizon rays. The correlation coefficients resulting from such a comparison are tabulated in table 3 and, it is seen that the average correlation coefficients are generally lower than those obtained previously. The general conclusion one reaches here, then, is that none of these other profile measures offers a significant improvement over the widely used $N_{s}$ and $\Delta N_{1.0}$.

\section{Use of Previous or Concurrent Radio Field Strengths to Predict the Annual Cycle of Radio Fields}

A perspective on the magnitude and usefulness of the above correlation coefficients may be gained by comparing the correlation of transmission loss recorded over nearly identical paths. Seven of the radio paths on table 1 had sufficient data so that the

\footnotetext{
${ }^{3}$ In the course of a private conversation, P. Misme has pointed out to the authors that recent studies have led him to adopt a different value for the altitude at which the parameter $d N / d h$ (referred to as $\triangle N_{c}$ in our equation for $G$ ) is measured. Furthermore, calculation by layers is in every case preferable as a method of obtaining the value of the "equivalent gradient." Unfortunately, this comment reached the authors too late to be considered in this work. However, a ment reached the authors too late to be considered in this work. However, a
forthcoming article by the authors will compare the variation of the equivalent gradient and other measures of atmospheric refraction with variations of transmission loss.
} 
TABLE 3. Coefficient of correlation between monthly median transmission loss and indicated meteorological variable

\begin{tabular}{|c|c|c|c|c|c|c|}
\hline Path & $G$ & $\Delta N_{0.2-0.5} *$ & $\Delta N_{0.5-1.0}$ & $\Delta N_{1.0-2.6}$ & $\Delta N_{2.0-3.0}$ & $N_{s}$ \\
\hline $\begin{array}{l}1 \\
2 \\
3 \\
4 \\
5\end{array}$ & $\begin{array}{r}0.5477 \\
.5273 \\
.6959 \\
.6489 \\
.5673\end{array}$ & $\begin{array}{c}0.04999 \\
-.1219 \\
.4511 \\
.3679 \\
.4166\end{array}$ & $\begin{array}{r}-0.2892 \\
-.2191 \\
.2437 \\
.1349 \\
.1988\end{array}$ & $\begin{array}{r}0.4042 \\
.3297 \\
.6747 \\
.5567 \\
.4450\end{array}$ & $\begin{array}{r}0.5032 \\
.5519 \\
.7425 \\
.5925 \\
.5455\end{array}$ & $\begin{array}{r}0.586 \\
.618 \\
.787 \\
.774 \\
.672\end{array}$ \\
\hline $\begin{array}{r}6 \\
7 \\
8 \\
9 \\
10\end{array}$ & $\begin{array}{l}.8383 \\
.5708 \\
.7351 \\
.6369 \\
.5312\end{array}$ & $\begin{array}{l}.5087 \\
.1986 \\
.6248 \\
.6583 \\
.4951\end{array}$ & $\begin{array}{l}.6355 \\
.1543 \\
.5134 \\
.5700 \\
.4531\end{array}$ & $\begin{array}{l}.7893 \\
.3675 \\
.6105 \\
.4834 \\
.5694\end{array}$ & $\begin{array}{l}.8666 \\
.6610 \\
.8102 \\
.6980 \\
.5681\end{array}$ & $\begin{array}{l}.940 \\
.714 \\
.726 \\
.588 \\
.506\end{array}$ \\
\hline $\begin{array}{l}11 \\
12 \\
13 \\
14 \\
15\end{array}$ & $\begin{array}{r}.5451 \\
.8178 \\
.6746 \\
.8400 \\
-.1262\end{array}$ & $\begin{array}{r}.4933 \\
.6308 \\
.3432 \\
-.2005 \\
-.3484\end{array}$ & $\begin{array}{r}.4207 \\
.6174 \\
.3610 \\
.6165 \\
-.4062\end{array}$ & $\begin{array}{r}.5743 \\
.5985 \\
-.5836 \\
.8162 \\
.7793\end{array}$ & $\begin{array}{l}.6074 \\
.7920 \\
.6850 \\
.8775 \\
.6321\end{array}$ & $\begin{array}{l}.525 \\
.868 \\
.785 \\
.935 \\
.797\end{array}$ \\
\hline \begin{tabular}{l|}
16 \\
17 \\
18 \\
19 \\
20 \\
21
\end{tabular} & $\begin{array}{l}.5636 \\
.2844 \\
.8213 \\
.5428 \\
.3636 \\
.7488\end{array}$ & $\begin{array}{r}.3844 \\
-.0350 \\
.7762 \\
-.8087 \\
.4088 \\
-.09026\end{array}$ & $\begin{array}{l}.5682 \\
.0044 \\
.7643 \\
.7599 \\
3519 \\
.8065\end{array}$ & $\begin{array}{l}.6797 \\
.3981 \\
.6950 \\
.5665 \\
.1786 \\
.6900\end{array}$ & $\begin{array}{l}.6889 \\
.6309 \\
.6336 \\
.7712 \\
.1188 \\
.6566\end{array}$ & $\begin{array}{l}.626 \\
.373 \\
.803 \\
.744 \\
.115 \\
.652\end{array}$ \\
\hline
\end{tabular}

Mean values (omitting path 20)

\begin{tabular}{l|r|r|r|r|r|r}
\hline$r(\bar{z})$ & 0.6224 & 0.3548 & 0.3811 & 0.5461 & 0.6624 & 0.694 \\
$k[r(\bar{z})]$ & $21.7 \%$ & $6.5 \%$ & $7.5 \%$ & $16.2 \%$ & $25.1 \%$ & $28.0 \%$
\end{tabular}

*Note: $\boldsymbol{N}_{0.2-0.5}$ indicates that the transmission loss was correlated with the difference in $N$ taken at $h=0.2 \mathrm{~km}$ and $h=0.5 \mathrm{~km}$.

first 12 months of record could be used to predict the monthly median radio field strengths in subsequent years. The results of this study, including the mean correlation coefficient and the improvement factor, are given in category 3 of table 4 . A comparison of the improvement factor with those of tables 2 and 3 leads one to the conclusion that for any practicel prediction problem, where only past radio or meteorological data are available, one obtains at least as good a prediction of the annual cycle of transmission loss from long-term meteorological data as from relatively short-term radio data.

This conclusion arises from the fact that the correlation between paths 1 and 2 is low (0.348) even though the paths are so nearly identical that one would not hesitate to make such a comparison for any

TABLE 4. Correlation of annual cycles of transmission loss over identical or nearly identical paths

\begin{tabular}{|c|c|c|c|c|c|}
\hline Category & Paths & Data & $j^{*}$ & $r$ & $\begin{array}{l}90 \% \text { confi- } \\
\text { dence limits }\end{array}$ \\
\hline 1 & $1 \& 2 \ldots$ & $\begin{array}{l}\text { Successive } 15 \text {-month peri- } \\
\text { ods. }\end{array}$ & 30 & 0.348 & 0.295 to 0.399 . \\
\hline 2 & $10 \& 11 \ldots$ & Coincident months. & 58 & .838 & 0.829 to 0.847 . \\
\hline 3 & $\left\{\begin{array}{l}3 \\
4 . \\
8 \\
9 \\
12 \\
15 \\
21\end{array}\right.$ & $\begin{array}{l}\text { First } 12 \text { months of record } \\
\text { on subsequent years of } \\
\text { record. }\end{array}$ & $\begin{array}{l}44 \\
17 \\
24 \\
12 \\
18 \\
16 \\
14\end{array}$ & $\begin{array}{l}.767 \\
.762 \\
.764 \\
.624 \\
.737 \\
.656 \\
.890\end{array}$ & $\begin{array}{l}0.750 \text { to } 0.783 \text {. } \\
0.708 \text { to } 0.807 \text {. } \\
0.730 \text { to } 0.795 \text {. } \\
0.500 \text { to } 0.723 \text {. } \\
0.683 \text { to } 0.783 \text {. } \\
0.578 \text { to } 0.723 \text {. } \\
0.859 \text { to } 0.917\end{array}$ \\
\hline & \multicolumn{5}{|c|}{$r \bar{z})=0.751$} \\
\hline
\end{tabular}

${ }^{*} j=$ pieces of data. engineering applications. The use of radio data from the same path (category 3) does yield a higher correlation than the use of meteorological data alone; but this type of prediction, running the actual circuit for a year, results in only a slight improvement in prediction at a cost increase of many orders of magnitude over that of procuring the necessary meteorological data. However, any actual radio path strength testing would probably fall into category 1 where data from nearly identical paths are used, and the resulting correlation appears to be less than that obtained from meteorological data alone. Category 2 , use of simultaneous radio data, yields the highest correlation but is generally an impractical procedure for engineering applications.

These results have a very important implication for future radio meteorological studies involving monthly median field strengths. It is hard to imagine any predictor of field strength variations that would be more effective than a nearby radio station at nearly the same frequency, recorded over nearly identical paths to the same receiver site. In this case it would seem that the maximum reduction in the uncertainty of predicting fields from monthly mean refractive index data could not exceed about 35 percent. If this is indeed true, then further work along these lines would seem quite futile, and new approaches should be tried. Perhaps a profitable new approach would be to combine the effects of day-to-day variations of refractive index profiles in some manner similar to that suggested in the earlier works of the senior author [15].

\section{Multiple Regression}

One might wonder if a combination of the above meteorological variables would produce a greater reduction of the uncertainty of prediction. Several combinations of meteorological parameters that might occur in practice were evaluated. These were transmission loss as a function of both $N_{s}$ and $\Delta N_{1.0}$ (assuming that both $N_{s}$ and $\Delta N$ could be obtained from climatic maps for the United States [1, 16] or the worldwide climatic maps in preparation by the International Consultative Committee for Radio) and also as a function of $N_{s}$ and $\Delta N_{0.1}$, such as might be obtained from meteorological towers. These data, reported in table 5 , indicate that very little improvement may be accomplished by using two meteorological variables determined from radiosonde data. Indeed, even when transmission loss as a function of all three of these meteorological parameters is considered, the augmentation of the correlation coefficient does not appear to be significant. In fact, the examination of the linear relationship involving all three of the meteorological factors,

$$
\begin{aligned}
-L_{b}= & b_{1} N_{s}+b_{2} \Delta N_{0.1}+b_{3} \Delta N_{1.0}+a \\
= & b_{1} N_{s}+b_{2} N_{s}-b_{2} N_{0.1}+b_{3} N_{s}-b_{3} N_{1.0}+a \\
= & N_{s}\left(b_{1}+b_{2}+b_{3}\right)-b_{2} N_{0.1}-b_{3} N_{1.0}+a,
\end{aligned}
$$


TABLE 5.-Correlation coefficients of transmission loss versus multiple meteorological factors

\begin{tabular}{|c|c|c|c|}
\hline Path & $r_{y \cdot x_{1} x_{2}}{ }^{*}$ & $r_{y \cdot x_{1} x_{3}}{ }^{*}$ & $r_{y \cdot x_{1} x_{2} x_{3}}{ }^{*}$ \\
\hline $\begin{array}{l}1 \\
2 \\
3 \\
4 \\
5\end{array}$ & $\begin{array}{r}0.586 \\
.636 \\
.797 \\
.794 \\
.696\end{array}$ & $\begin{array}{r}0.613 \\
.633 \\
.787 \\
.812 \\
.790\end{array}$ & $\begin{array}{r}0.622 \\
.669 \\
.800 \\
.814 \\
.790\end{array}$ \\
\hline $\begin{array}{r}6 \\
7 \\
8 \\
9 \\
10\end{array}$ & $\begin{array}{l}.958 \\
.758 \\
.733 \\
.627 \\
.528\end{array}$ & $\begin{array}{r}.958 \\
.716 \\
.818 \\
.688 \\
.607\end{array}$ & $\begin{array}{r}.959 \\
.782 \\
.822 \\
.764 \\
.610\end{array}$ \\
\hline $\begin{array}{l}11 \\
12 \\
13 \\
14 \\
15\end{array}$ & $\begin{array}{l}.542 \\
.869 \\
.787 \\
.936 \\
.823\end{array}$ & $\begin{array}{r}.626 \\
.874 \\
.785 \\
.936 \\
.816\end{array}$ & $\begin{array}{l}.628 \\
.875 \\
.787 \\
.936 \\
.837\end{array}$ \\
\hline $\begin{array}{l}16 \\
17 \\
18 \\
19 \\
20 \\
21\end{array}$ & $\begin{array}{l}.690 \\
.435 \\
.812 \\
.749 \\
.500 \\
.771\end{array}$ & $\begin{array}{l}.730 \\
.592 \\
.803 \\
.766 \\
.315 \\
.718\end{array}$ & $\begin{array}{r}.798 \\
.736 \\
.813 \\
.770 \\
.500 \\
.778\end{array}$ \\
\hline \multicolumn{4}{|c|}{ Mean values (omitting path 20) } \\
\hline $\begin{array}{l}r^{\prime}(\bar{z}) \\
k[r(\bar{z})]\end{array}$ & $\begin{array}{r}0.717 \\
30.3 \%\end{array}$ & $\begin{array}{r}0.742 \\
33.0 \%\end{array}$ & $\begin{array}{r}0.758 \\
34.8 \%\end{array}$ \\
\hline
\end{tabular}

${ }^{*}$ For this table $y=L_{b}, x_{1}=N_{s}, x_{2}=\Delta N_{0.1}$ $x_{3}=\Delta N_{1} .0$.

discloses that the attempt to specify the refractive profile by three points apparently does not lead to an appreciable increase in the correlation coefficient. However, the error analysis carried out in the next section indicates that the probable errors associated with radiosonde measurements are sufficient to mask the true correlation value to the extent that this conclusion might well be modified by the use of more accurate meteorological data.

The above correlations do reflect systematic properties of the atmosphere which in themselves present an interesting study. It is not too surprising to note that the mean correlation coefficient between $N_{s}$ and $\Delta N_{1.0}$ is high $(0.9840)$. This interdependence of $N_{s}$ and $\Delta N_{1.0}$ is fortunate since it allows the computation of $\Delta N_{1.0}$ from surface data, which is readily available throughout the world.

\section{Error Analysis}

It is really quite surprising that the initial gradient, $\Delta N_{0.1}$, did not yield larger correlation coefficients since the refraction of radio waves is known to be extremely sensitive to the initial gradient. It is quite possible that this low correlation reflects the difficulty of determining an $N$ difference over a small increment with relatively inaccurate radiosonde sensing elements. We may analyze this error by reference to common meteorological standard atmospheres and standards of measurement set by the International Consultative Committee for Radio (CCIR). By setting

$$
\Delta N_{1-2}=\frac{\left(N_{1}+\epsilon_{1}\right)-\left(N_{2}+\epsilon_{2}\right)}{\left(h_{1}-h_{2}\right)}
$$

where $N_{1}$ and $N_{2}$ represent the true value of $N$ at $h_{1}$ and $h_{2}$ and $\epsilon_{1}$ and $\epsilon_{2}$ represent the errors determining $N$ at $h_{1}$ and $h_{2}$ respectively, then the standard deviation of the error in $\Delta N_{1-2}$ is

$$
\sigma\left(\Delta N_{1-2}\right)=\left[\frac{\sigma^{2}\left(\epsilon_{1}\right)+\sigma^{2}\left(\epsilon_{2}\right)}{\left(h_{1}-h_{2}\right)^{2}}\right]^{1 / 2}
$$

assuming that $h_{1}-h_{2}$ is known exactly and that $\epsilon_{1}$ and $\epsilon_{2}$ are uncorrelated. The errors $\epsilon_{1}$ and $\epsilon_{2}$ may be determined by noting that [6]

$$
N=K_{1} \frac{P}{T}+K_{2} \frac{e}{T^{2}}
$$

and that

$$
d N=\frac{\partial N}{\partial T} d T+\frac{\partial N}{\partial e} d e+\frac{\partial N}{\partial P} d P .
$$

The partial derivatives may be evaluated from the ICAO standard atmosphere [17] assuming 60 percent relative humidity to yield approximate relationships

$$
\Delta N=-1.27 \Delta T+4.50 \Delta e+0.27 \Delta P
$$

for $h=0$ and

$$
\Delta N=-1.09 \Delta T+4.72 \Delta e+0.28 \Delta P
$$

for $h=1 \mathrm{~km}$.

By assuming the relatively stringent accuracies in measuring $P, T$, and $e$ called for by the CCIR [18] one obtains standard errors of 3.5 percent of the mean in determining $\Delta N_{1.0}$, and 22.7 percent of the mean in determining $\Delta N_{0.1}$.

Reference to standard treatment of the effect of measurement errors upon correlation coefficients [19] shows that if $y$ is the dependent variable and the indpendent variable $x^{*}=x+\epsilon$ where $x$ is the true value and $\epsilon$ is the measurement error then the correlation coefficient is

$$
\rho_{y \cdot x}{ }^{*}=\frac{\rho_{y \cdot x}}{\sqrt{1+s^{2}(\epsilon) / s^{2}(x)}}
$$

assuming that $\epsilon$ has zero mean and variance $s^{2}(\epsilon)$ and is uncorrelated with either $x$ or $y$, the other terms having their usual meaning. It is seen that the effect of measurement error is to reduce the correlation coefficient by the factor

$$
\frac{1}{\sqrt{1+s^{2}(\epsilon) / s^{2}(x)}} \cdot
$$

If we now assume that $y$ (in this case the transmission loss) is correlated with two different measures of the same variable, $x_{1}$ and $x_{2}$, (in this case $\Delta N_{0.1}$ and $\Delta N_{1.0}$ ) then from the ratio

$$
\frac{\rho_{y . x_{1}^{*}}}{\rho_{y . x_{2}^{*}}}=\frac{\rho_{y . x_{1}}}{\rho_{y . x_{2}}}\left[\frac{1+s^{2}\left(\boldsymbol{\epsilon}_{2}\right) / s^{2}\left(\boldsymbol{x}_{2}\right)}{1+s^{2}\left(\boldsymbol{\epsilon}_{1}\right) / s^{2}\left(x_{1}\right)}\right]^{1 / 2} .
$$


one may determine the relative size of the measurement errors necessary to yield the same correlation coefficient by setting

$$
\frac{\rho_{y \cdot x_{1}^{*}}}{\rho_{y \cdot x_{2}^{*}}}=\frac{\rho_{y \cdot x_{1}}}{\rho_{y \cdot x_{2}}}=1
$$

and obtaining

$$
s\left(\epsilon_{1}\right) / s\left(\epsilon_{2}\right)=s\left(x_{1}\right) / s\left(x_{2}\right) .
$$

Returning to our data we find that this ratio averages about 1.5 for the observed values of $s\left(\Delta N_{0.1}\right) /$ $s\left(\Delta N_{1.0}\right)$ while the ratio of the errors determined from the ICAO standard atmosphere and the CCIR standards of measurement is about 10.0. Thus it is seen that the errors of measurement may indeed be the cause of the differences in these correlation coefficients. Although one cannot estimate the actual size of the true correlation coefficients, one can estimate their ratio by reexpressing (14) as

$$
\frac{\rho_{y \cdot x_{1}}}{\rho_{y . x_{2}}}=\frac{\rho_{y \cdot x_{1}^{*}}}{\rho_{y \cdot x_{2}^{*}}}\left[\frac{1+s^{2}\left(\epsilon_{1}\right) / s^{2}\left(x_{1}\right)}{1+s^{2}\left(\epsilon_{2}\right) / s^{2}\left(x_{2}\right)}\right]^{1 / 2} \text {. }
$$

When we again use the standard-atmosphere-estimated errors and the actual values of $s^{2}\left(x_{1}\right)$ and $s^{2}\left(x_{2}\right)$ for the 21 paths in our analysis, we find that the ratio $\rho_{y \cdot x_{1}} / \rho_{y \cdot x_{2}}$ averages about 1.5 which implies, since $r_{L_{b}, \Delta N_{1.0}} \sim 0.7$, the actual correlation with the surface layer $r_{L_{b} . \Delta N_{0.1}}$ is near unity, an observation that should guide future experimental research in the quest of more efficient radio-meteorological parameters.

Although it is evident that the errors of measurement do make the choice of a radio climatological parameter based upon this study somewhat indefinite, we may use the present study as an objective criterion of the relative merits of such parameters when determined from radiosonde observations. Perhaps the advent of more accurate measurements will shed more light on the true role of the surface layer in radio meteorology.

\section{Extension to Other Regions}

Although this study encompasses only a small portion of the United States because of limited radio data, several of the more important climates of the world are represented by the 21 paths. Paths 1 to 6 , 14, 17, and 21 lie in the same humid subtropical region which covers parts of Argentina, China, and Yugoslavia; the climate of paths 7 to 13,16 , and 18 is similar to that of Hungary, Romania, and parts of Japan; path 15 represents the Mediterranean regions and includes southern Australia, Africa, and central Chile; path 20 has meteorological conditions which resemble the middle latitude steppes of Canada and southern Russia while path 19 is similar to southern Sweden and central Russia. It is reasonable to assume that the general pattern of the mean profile of a climatic area would repeat itself, regard- less of the country in which it was located. Such an assumption would permit the extension of any conclusions reached in this paper regarding the correlative aspects of various meteorological parameters versus transmission loss to other regions. In fact, studies which have been completed of $N_{s}$ versus transmission loss show good results not only in the Florida-Caribbean [3] area but also with transmission paths from Argentina to Uruguay [3], from Minorca to Sardinia in the Mediterranean [4], and from Tokyo to Osaka in Japan [20].

\section{Conclusions}

In this study the calculation of the correlation coefficients of recorded transmission loss over 21 radio paths versus various properties of the refractive index profile up to $3 \mathrm{~km}$ provides a means of evaluating which radio-meteorological parameter is most efficient to predict average radio transmission loss. The best correlations appeared to be associated with the time-honored values of $\Delta N_{1,0}$ and $N_{s}$, indicating that tbey continue to vield as good a correlation as any other parameter derived from currently available radiosonde observations.

While comparing the interdependence of meteorological parameters, the correlation of surface refractivity, $N_{s}$, with a gradient interval of $1 \mathrm{~km}$ was found to ba high, explaining why the mor a accessible $N_{s}$ can be used with significant results in place of the $1-\mathrm{km}$ gradient in the prediction of transmission loss.

An examination of the correlations of transmission loss recorded for 1 year versus that recorded in another year for the same radio path revealed correlations of the same order as those obtained from meteorological data alone, indicating the very practical result that inexpensive meteorological data may be used to predict the seasonal variation of radio fields as accurately as expensive radio path measurements.

The authors acknowledge the assistance of K. A. Norton, G. Richmond, B. J. Weddle, and P. C. Whittaker in this study.

\section{References}

[1] B. R. Bean and F. M. Meaney, Some applications of the monthly median refractivity gradient in tropospheric propagation, Proc. IRE 43, 1419 (1955).

[2] K. A. Norton, P. L. Rice, and L. E. Vogler, Use of angular distance in estimating transmission loss and fading range for propagation through a turbulent atmosphere over irregular terrain, Proc. IRE 43, 1488 (1955).

[3] R. E. Gray, Refractive index of the atmosphere as a factor in tropospheric propagation far beyond the horizon, Elec. Commun. 36, 60 (1959).

[4] L. Bonavoglia, Correlazione fra fenomeni meteorologici e propagazione oltre l'orizzonte sul Mediterraneo, Alta Frequenza XXVII, 815 (1958).

[5] F. du Castel, Sur la validite de l'hypothese d'une gradient lineaire de l'indice de refraction tropospherique pour le calcul du champ dans la zone de diffraction en ondes metriques en Mediterranee occidentale, Note Prelim. No. 175 (Lab. Natl. Radioelec., France, 1954). 
[6] E. K. Smith and S. Weintraub, The constants in the equation for atmospheric refractive index at radio frequencies, Proc. IRE 41, 1035 (1953).

[7] G. W. Pickard and H. T. Stetson, Comparison of tropospheric reception, J. Atmospheric and Terrest. Phys. 1, 32 (1950)

[8] G. W. Pickard and H. T. Stetson, Comparison of tropospheric reception at $44.1 \mathrm{Mc}$ with $92.1 \mathrm{Mc}$ over the 167-mile path of Alpine, New Jersey to Needham, Massachusetts, Proc. IRE 38, 1450 (1950).

[9] K. A. Norton, Point-to-point radio relaying via the scatter mode of tropospheric propagation, IRE Trans. PGCS-4, 39 (1956).

[10] G. W. Snedecor, Statistical Methods, p. 152 (Iowa State College Press, Ames, Iowa, 1946).

[11] J. B. Smyth and L. G. Trolese, Propagation of radio waves in the lower atmosphere, Proc. IRE 35, 1198 (1947).

[12] L. J. Anderson and E. E. Gossard, Prediction of oceanic duct propagation from climatological data, IRE Trans. AP-3, 163 (1955).

[13] Untersuchungen uber die Wetterabhangigkeit der Feldstarke im 100-MHz-Band auf der Strecke BielsteinDarmstadt, Tech. Ber. 5518, Fernmeldetech. Zentralamt der Deutschen Bundespost, 20 Marz 1956.
[14] P. Misme, The correlation between the electric field at a great distance and a new radio-meteorological parameter, Trans. IRE AP-6, 289 (1958).

[15] B. R. Bean, Sur L'Utilisation Des Observations Meteorologiques Courantes En Propagation, Radioelectrique, Onde Elec. 37 e Annee, 362, 411 (1957).

[16] B. R. Bean, and G. D. Thayer, On models of the atmospheric radio refractive index, Proc. IRE 47, 740 (1959).

[17] U.S. Extension to the ICAO Standard Atmosphere, Tables and data to 300 standard geopotential kilometers, U.S. Weather Bureau, Washington, D.C. (1958).

[18] International Radio Consultative Committee, Documents of the IX Plenary Assembly, Los Angeles (1959); Vol. II, Study Programme No. 138 (v), Tropospheric Wave Propagation, ITU, Geneva (1959).

[19] A. Hald, Statistical theory with engineering applications (John Wiley and Sons, New York, N.Y., 1952).

[20] M. Onoe, M. Hirai, and S. Niwa, Results of experiment of long-distance overland propagation of ultra-short waves, J. Radio Research Labs., Japan 5, 79 (1958).

(Paper 65D1-104) 